\title{
Toward Broad Spectrum DHFR inhibitors Targeting Trimethoprim Resistant Enzymes Identified in Clinical Isolates of Methicillin-Resistant Staphylococcus aureus
}

Stephanie M. Reeve ${ }^{1}$, Debjani $\mathrm{Si}^{1}$, Jolanta Krucinska ${ }^{1}$, Yongzhao Yan ${ }^{1}$, Kishore Viswanathan ${ }^{1}$, Siyu Wang ${ }^{2,3}$, Graham T. Holt ${ }^{2,3}$, Marcel S. Frenkel ${ }^{4}$, Adegoke A. Ojewole ${ }^{2,3}$, Alexavier Estrada ${ }^{1}$, Sherry S. Agabiti ${ }^{1}$, Jeremy B. Alverson ${ }^{5}$, Nathan D. Gibson $^{5}$, Nigel D. Priestly ${ }^{5}$, Andrew J. Wiemer ${ }^{1}$, Bruce R. Donald ${ }^{2,4,6}$, Dennis L. Wright ${ }^{1,7^{*}}$

${ }^{1}$ Department of Pharmaceutical Sciences, University of Connecticut, Storrs, CT 06269 USA

${ }^{2}$ Department of Computer Science, Duke University, Durham, NC 27708 USA

${ }^{3}$ Program in Computational Biology and Bioinformatics, Duke University, Durham, NC 27708 USA

${ }^{4}$ Department of Biochemistry, Duke University Medical Center, Durham, NC 27710 USA

${ }^{5}$ Department of Chemistry, University of Montana, Missoula, MT 59812, USA

${ }^{6}$ Department of Chemistry, Duke University, Durham, NC 27708 USA

${ }^{7}$ Department of Chemistry, University of Connecticut, Storrs, CT 06269 USA

${ }^{*}$ Corresponding Author

Figure S1 Sequence similarity comparison of DHFR enzymes used in this study 2

Figure S2 Sequence alignment of DHFR enzymes used in this study 3

Figure S3 DHFR expression in response to antifolate exposure 4

Figure S4 Overlay of $\mathbf{1 3}$ and $\mathbf{1 4}$ with active site amino acids 5

Figure S5 Overlay of dihydrofolate and methotrexate in the DfrB active site 6

Table S1 DfrB and Human DHFR IC 50 Values used to Calculate Human Selectivity 7

Table S2 Crystallography Data Collection and Refinement Statistics 8

Molecular Dynamic Ligand Reorganization upon Binding of DHFR 9

Figure S6 Minimum energy structures using biphenyl and propargylic dihedral drive 10

Table S3 Comparison of dihedral angles in minimum energy and bioactive conformations 11

Biological and Computational Methods $\quad 12$

Synthetic Methods and Compound Characterization 14

Figures S7-S12 ${ }^{1} \mathrm{H}$ NMR Spectra of Novel compounds $\quad 18$ 


\begin{tabular}{l|llll} 
& DfrB & DfrA & DfrG & DfrK \\
\hline DfrB & 100 & 79.9 & 41.5 & 42.1 \\
DfrA & 79.9 & 100 & 38.5 & 39.8 \\
DfrG & 41.5 & 38.5 & 100 & 89.6 \\
Dfrk & 42.1 & 38.9 & 89.6 & $\mathbf{1 0 0}$
\end{tabular}

Supplemental Figure 1 Sequence similarity (in \%) between S. aureus associated DHFR enzymes in this study 

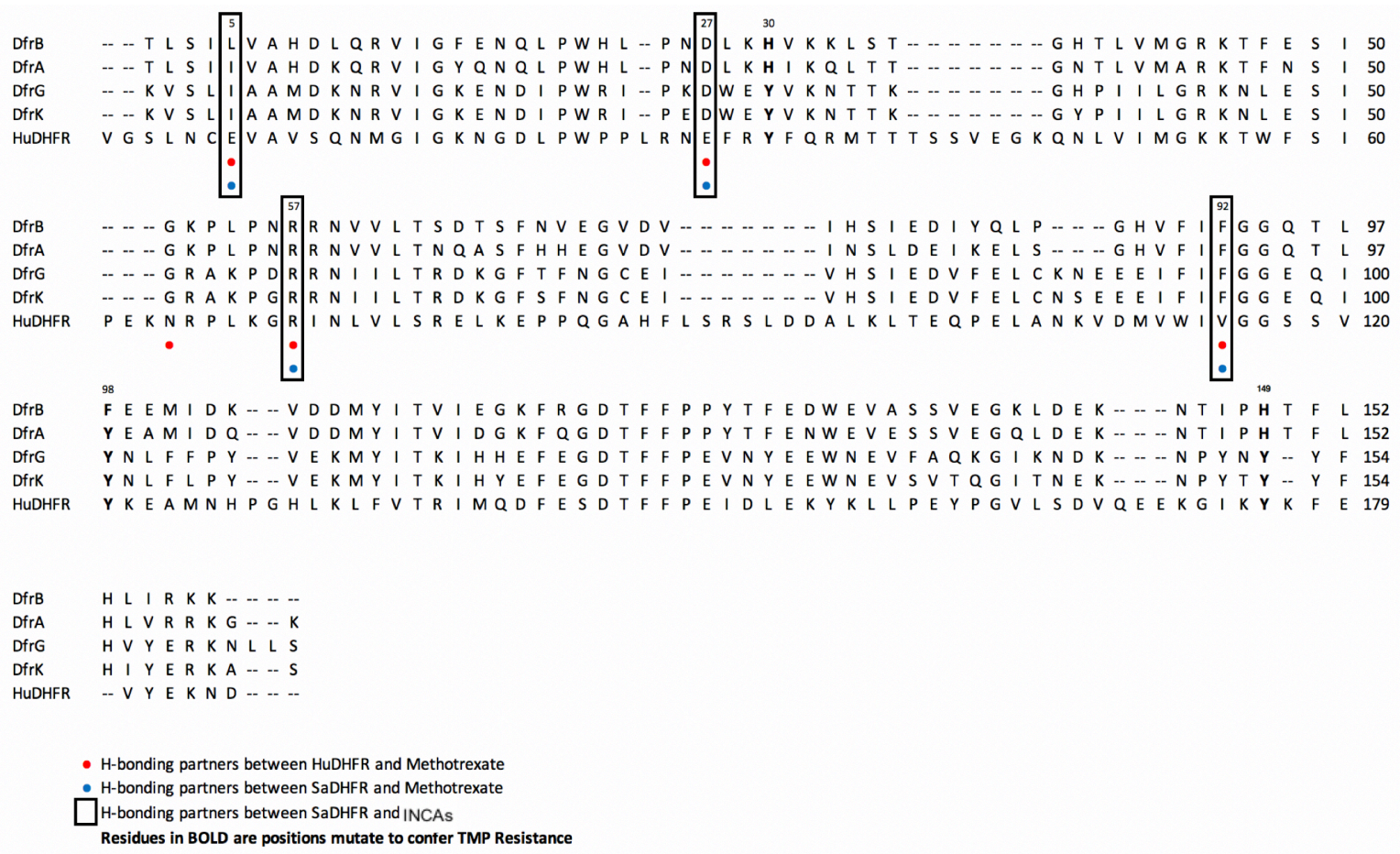

Supplemental Figure 2 Alignment of DHFR enzymes used in this study. This figure also highlights the hydrogen bonding interactions between methotrexate, human DHFR and DfrB as well as DfrB and the INCA compounds 

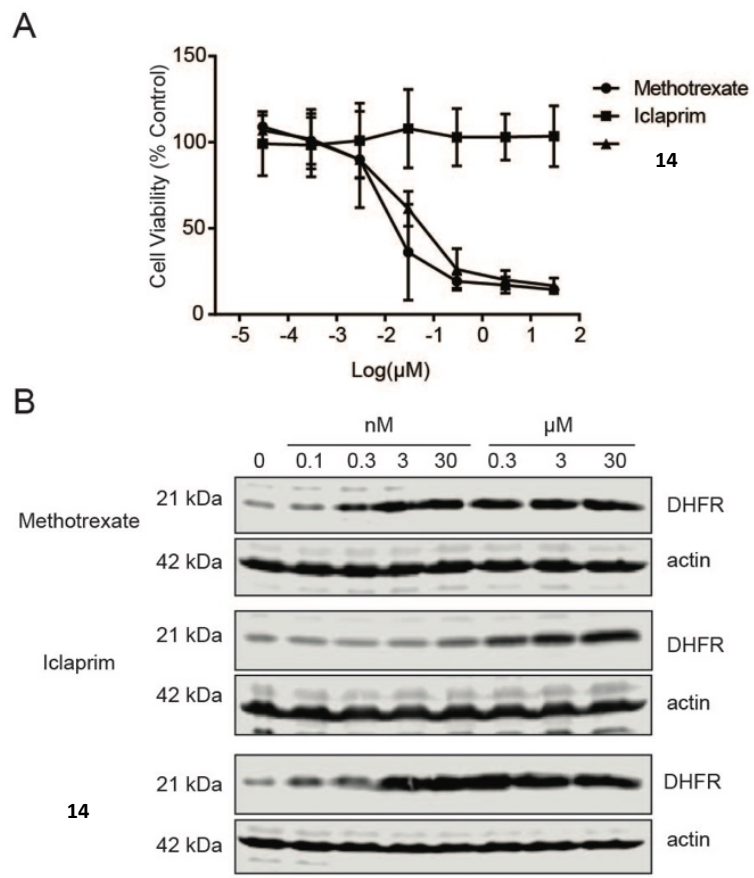

C

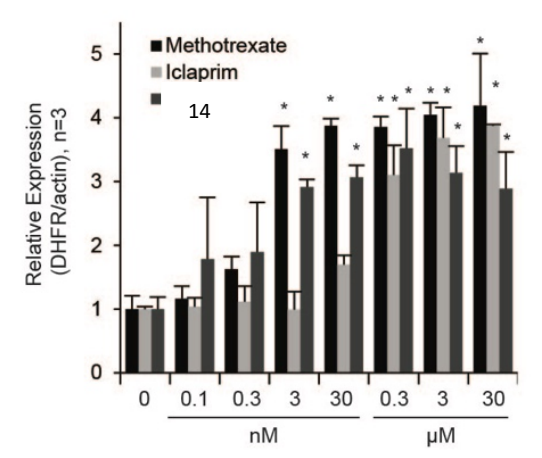

Supplemental Figure 3 Changes in viability and expression of DHFR induced by methotrexate, iclaprim and 14. A) Cell viability of HL-60 cells treated with methotrexate, iclaprim, and $\mathbf{1 4}$ for 72 hours. B) Western blot analysis of DHFR expression in HL-60 cells for test compounds incubated for 72 hours. Blots shown are representative of 3 replicates. C) Quantification of DHFR expression in HL-60 cells treated with indicated compounds for 72 hours, $n=3 . * P<0.05$ by ANOVA and Tukey's post-hoc analysis 


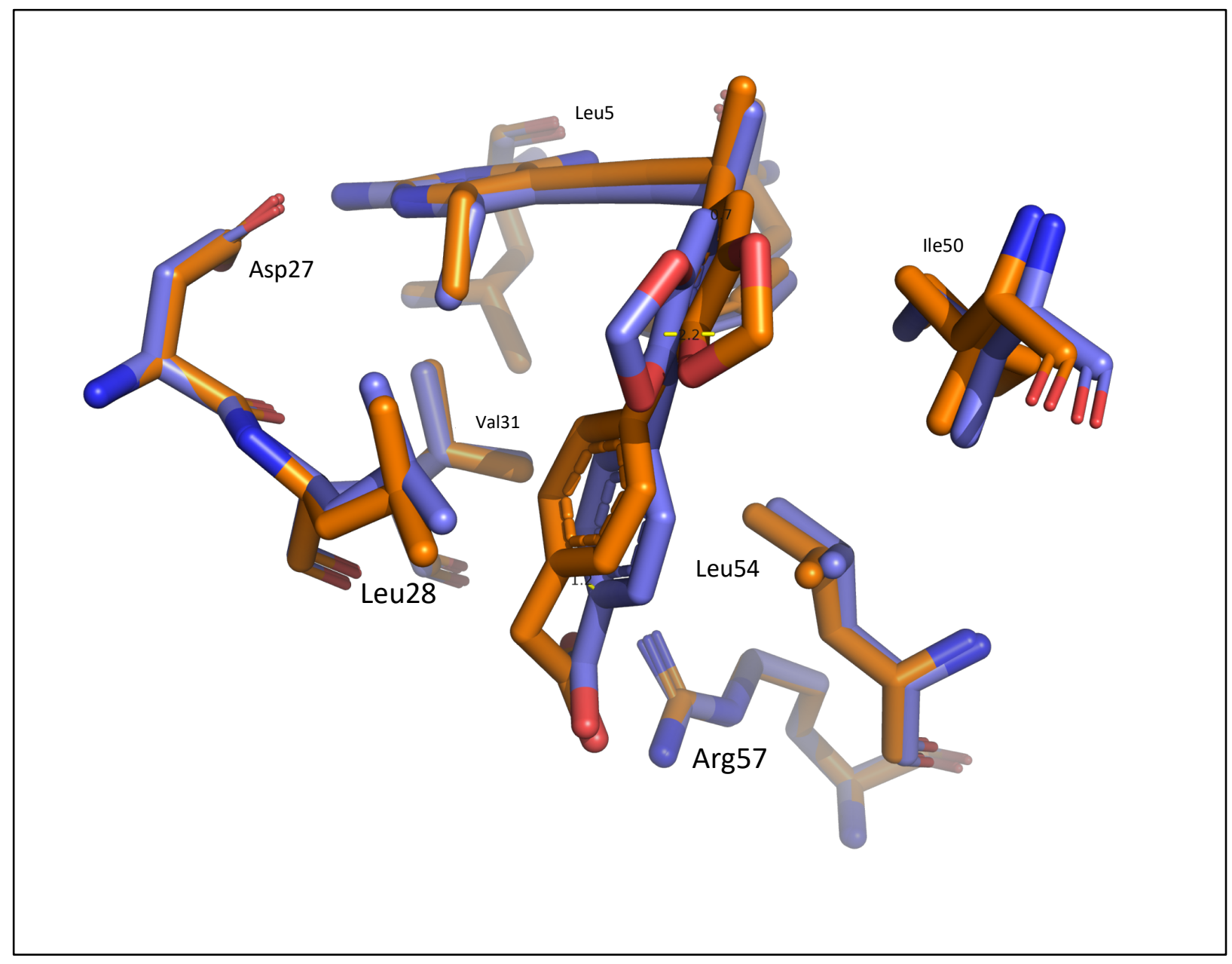

Supplemental Figure 4 Compounds 13 (Purple) and 14 (Orange) in the DfrB active site. 


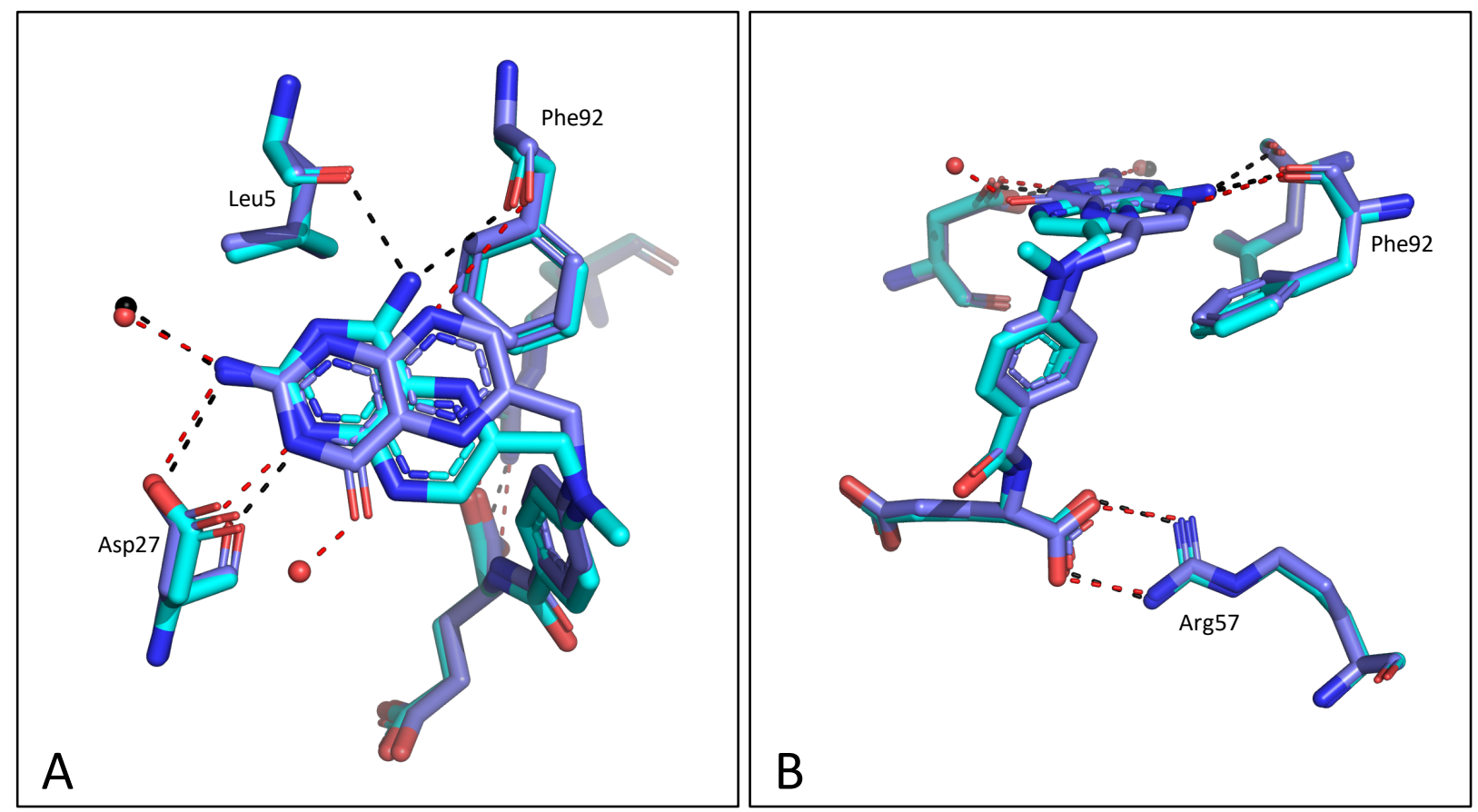

Supplemental Figure 5 Comparison of methotrexate (blue, water and $\mathrm{H}$-bonding interactions in black) and folate (purple, water and $\mathrm{H}$-bonding interactions in red) in the DfrB active site. Panel A) hydrogen bonding patterns for in the pterin binding pocket. MTX has the same binding mode as TMP and the INCA compounds, whereas folate binds in an opposite orientation in the pterin binding pocket. Panel B) bonding interactions in the distal portion of the binding site, dual hydrogen bonding interactions with Arg57 are highlighted. 
Supplemental Table 1 DfrB and Human DHFR IC $5_{50}$ Values used to Calculate Human Selectivity (nM)

\begin{tabular}{c|ccccc} 
& DfrB & DfrA & DfrG & DfrK & HuDHFR \\
\hline 1 & $18 \pm 1$ & $3980 \pm 260$ & $195 \pm 17$ & $149 \pm 16$ & $305 \pm 20$ \\
2 & $25.3 \pm 0.8$ & $180 \pm 18$ & $157 \pm 15$ & $63 \pm 2$ & $607 \pm 55$ \\
3 & $170 \pm 13$ & $9530 \pm 580$ & $19 \pm 2 \mu \mathrm{M}$ & $2845 \pm 250$ & $750 \pm 55$ \\
4 & $53 \pm 4$ & $211 \pm 6$ & $3240 \pm 200$ & $157 \pm 6$ & $507 \pm 20$ \\
5 & $89 \pm 2$ & $53 \pm 2$ & $88 \pm 6$ & $19 \pm 8$ & $244 \pm 22$ \\
6 & $10 \pm 1$ & $2840 \pm 50$ & $177 \pm 20$ & $16 \pm 1$ & $992 \pm 24$ \\
7 & $15 \pm 0.5$ & $179 \pm 8$ & $158 \pm 15$ & $34 \pm 3$ & $283 \pm 45$ \\
8 & $8.9 \pm 0.7$ & $400 \pm 10$ & $217 \pm 20$ & $30 \pm 1$ & $449 \pm 20$ \\
9 & $14 \pm 1$ & $270 \pm 20$ & $193 \pm 12$ & $91 \pm 8$ & $646 \pm 50$ \\
10 & $19 \pm 1$ & $40 \pm 3$ & $492 \pm 40$ & $43 \pm 2.9$ & $315 \pm 16$ \\
11 & $18 \pm 1$ & $56 \pm 6$ & $898 \pm 30$ & $82 \pm 4.4$ & $446 \pm 24$ \\
12 & $34 \pm 1$ & $290 \pm 20$ & $186 \pm 15$ & $40 \pm 2$ & $691 \pm 62$ \\
13 & $10 \pm 0.2$ & $320 \pm 30$ & $78 \pm 5$ & $41 \pm 6$ & $739 \pm 62$ \\
14 & $17 \pm 1$ & $191 \pm 14$ & $40 \pm 6$ & $18 \pm 2$ & $484 \pm 10$ \\
MTX & $6 \pm 0.7$ & $53 \pm 2$ & $23 \pm 2$ & $25 \pm 1$ & $24 \pm 0.1$ \\
TMP & $23 \pm 2$ & $15.1 \pm 0.7 \mu \mathrm{M}$ & $380 \pm 17 \mu \mathrm{M}$ & $43 \pm 2 \mu \mathrm{M}$ & $83 \pm 6 \mu \mathrm{M}$ \\
Iclaprim & $16 \pm 1$ & $1640 \pm 60$ & $17 \pm 2 \mu \mathrm{M}$ & $2231 \pm 60$ & $341 \pm 5 \mu \mathrm{M}$
\end{tabular}


Supplemental Table 2 Crystallography Data Collection and Refinement Statistics

\begin{tabular}{|c|c|c|}
\hline & \multicolumn{2}{|c|}{ Sa(WT)DHFR Crystal Structures } \\
\hline & DfrB: NADPH:14 & DfrB: NADPH:MTX \\
\hline PDB ID & 6PBO & $6 \mathrm{P9Z}$ \\
\hline Space group & $P 6122$ & $P 6122$ \\
\hline No. monomers in asymmetric unit & 1 & 1 \\
\hline Unit cell $(a, b, c$ in $\AA)$ & $\begin{array}{c}78.94,78.94,108.27 \\
90,90,120\end{array}$ & $\begin{array}{c}79.03,79.03,109.09 \\
90,90,120\end{array}$ \\
\hline Resolution $(\AA ̊)$ & $1.65-42.44$ & $1.86-32.65$ \\
\hline Completeness \% (last shell, \%) & 97.07 (99) & $99.32(98)$ \\
\hline Unique reflections & 23,956 & 17,429 \\
\hline Redundancy & 11.2 & 14.1 \\
\hline Rsym, (last shell) & $0.117(0.688)$ & $0.124(0.689)$ \\
\hline$<I / \sigma>$ (last shell) & $10.9(1.2)$ & $40.8(5.0)$ \\
\hline R-factor/Rfree & $0.2509 / 0.2894$ & $0.1876 / 0.2182$ \\
\hline No. of atoms (protein, ligands, solvent) & 1,528 & 1,486 \\
\hline Rms deviation bond lengths $(\AA)$, angles (deg) & $0.008,1.790$ & $0.007,1.031$ \\
\hline Average $B$ factor for protein $(\AA 2)$ & 25.26 & 27.47 \\
\hline Average $B$ factor for ligand $(\AA 2)$ & $\begin{array}{c}\text { NADPH: } 19.67 \\
\text { 14: } 26.51\end{array}$ & $\begin{array}{c}\text { NADPH: } 20.98 \\
\text { MTX: } 27.89\end{array}$ \\
\hline Average $B$ factor for solvent molecules $\left(\AA^{2}\right)$ & 32.51 & 34.58 \\
\hline Residues in most favored regions (\%) ${ }^{a}$ & 98.06 & 98.71 \\
\hline Residues in additional allowed regions $(\%)^{a}$ & 1.94 & 1.29 \\
\hline Residues in disallowed regions $(\%)^{a}$ & 0 & 0 \\
\hline Collection Location & SSRL 14-1 & SSRL 14-1 \\
\hline
\end{tabular}




\section{Molecular Dynamic Ligand Reorganization upon Binding of DHFR}

We were interested in examining the conformational re-organization that these ligands undergo upon binding with bacterial DHFR and evaluating their associated energy penalties. Therefore, two different dihedrals angles, the dihedral angle between propargylic methyl and the adjacent aromatic ring, and the dihedral angle between biphenyl rings were chosen for analysis. Molecular dynamic calculations performed on a paired set of benzoic acid and phenyl acetic acid ligands, 13 and 14, and ligand 10. Two separate minimum energy conformers for each ligand were generated and were further compared with their bioactive conformers. We observed (Supplemental Table 3 and Supplemental Figure 6) that to gain the overall stabilization in the active site of the bacterial DHFR the narrow dihedral angles ( 4 to- $18^{\circ}$ ) between propargylic methyl and the adjacent aromatic ring were well tolerated in all of the bioactive conformers of phenyl acetic acid ligands overriding the conformational bias of larger ( 99 to $110^{\circ}$ ) dihedral angles in the minimum energy structures. In order to make optimal interactions with the distal arginine via the dual $\mathrm{H}$-bonding this dihedral angle expanded from $3.5^{\circ}$ in shorter benzoic acid, 13 to $16.1^{\circ}$ in phenyl acetic acid, 14. Further, this stabilizing event also narrowed the dihedral angles between the biphenyl systems by 8 to $14^{\circ}$ for phenyl acetic acid INCAs. However, such reduction of biphenyl dihedral angle was not observed for benzoic acid ligand 13. 


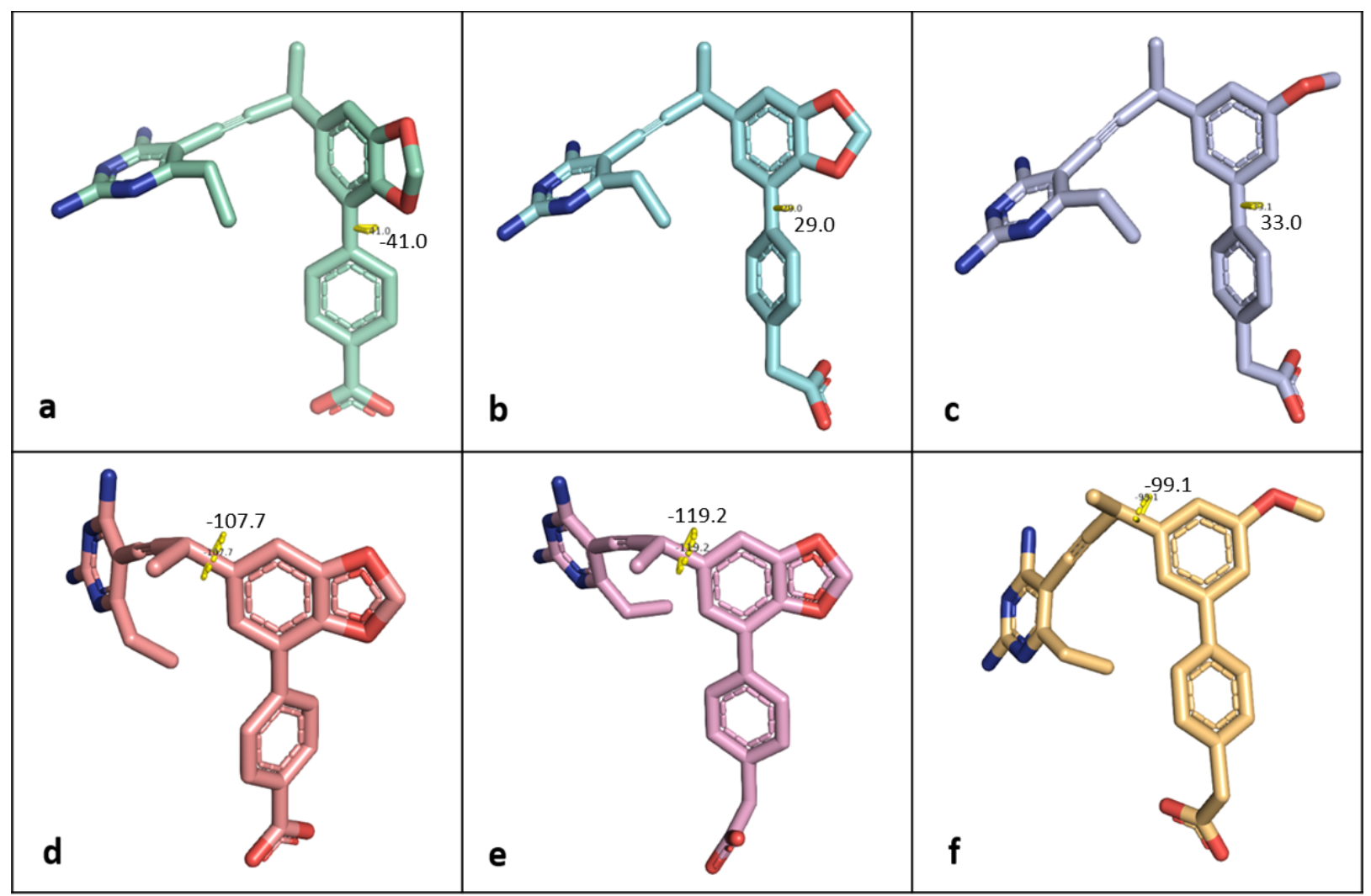

Supplemental Figure 6 Minimum energy structures generated using biphenyl dihedral drive for ligands a) $\mathbf{1 3}$ b) 14 and c) $\mathbf{1 0}$. Minimum energy structures generated using propargylic dihedral drive for ligands d) 13,e) 14 and f) 10 
Supplemental Table 3 Comparison of dihedral angles in minimum energy and bioactive conformations

\begin{tabular}{|c|c|c|c|}
\hline \multirow{2}{*}{ Ligand } & $\begin{array}{c}\text { Type of Dihedral } \\
\text { angle }\end{array}$ & $\begin{array}{c}\text { Dihedral angle } \\
\text { (minimum energy } \\
\text { structure) in degrees }\end{array}$ & $\begin{array}{c}\text { Dihedral angle (bio- } \\
\text { active conformation) } \\
\text { in degrees }\end{array}$ \\
\hline \multirow{2}{*}{13} & propargyl & -107.7 & 3.5 \\
\cline { 2 - 4 } & biphenyl & -41.0 & -37 \\
\hline \multirow{2}{*}{14} & propargyl & -119.2 & -16.1 \\
\cline { 2 - 4 } & biphenyl & 29.0 & -20.3 \\
\hline \multirow{2}{*}{10} & propargyl & -99.1 & -18.7 \\
\cline { 2 - 4 } & biphenyl & 33.0 & -15.6 \\
\hline
\end{tabular}




\section{Supplemental Biological Data}

\section{HL-60 DHFR Expression and Viability}

Dihydrofolate reductase antibody (clone \# 872442) was obtained from R\&D Systems (Minneapolis, MN, USA). Beta-actin (Poly6221) was obtained from Biolegend (San Diego, CA, USA). CellQuantiBlue was obtained from BioAssay Systems (Hayward, CA, USA). HL-60 cells were obtained from American Type Culture Collection (Manassas, VA, USA) and cultured with in complete media (RPMI-1640, 10\% FBS, 1x penicillin/streptomycin, 1x non-essential amino acids, 1x sodium pyruvate, $0.0004 \%$ BME, $10 \mathrm{mM} \mathrm{HEPES} \mathrm{pH} \mathrm{7.5)} \mathrm{at} 5 \times 10^{5}$ cells/mL. 20,000 cells/well of HL-60 cells in log phase growth were seeded in 96 well plates in $100 \mu \mathrm{L}$ of fresh media in the presence of DHFR inhibitors. Cells were cultured for 72 hours and during the last 2 hours, $10 \mu \mathrm{L}$ of CellQuantiBlue reagent was added to each well. The plates were then scanned with a Victor PerkinElmer (Waltham, MA, USA) plate reader (ex550/em600).

Cells were resuspended at $2 \times 10^{5}$ cells $/ \mathrm{mL}$ in fresh media. Cells were cultured for 72 hours with indicated concentrations of test compounds or solvent controls. Cells were washed once in PBS and resuspended in in lysis buffer $(25 \mathrm{mM}$ Tris- $\mathrm{HCl}$ pH 7.6, $150 \mathrm{mM} \mathrm{NaCl}, 1 \% \mathrm{NP}-40,1 \%$ sodium deoxycholate) for 10 minutes on ice followed by centrifugation for 10 minutes at 14,000 x g. Lysis buffer contained a panel of freshly added protease and phosphatase inhibitors including leupeptin $(1 \mu \mathrm{g} / \mathrm{mL})$, aprotinin $(1 \mu \mathrm{g} / \mathrm{mL})$, PMSF $(200 \mu \mathrm{M})$ (all from Fisher). Protein levels were quantified by BCA assay and equivalent masses were loaded onto $12 \%$ SDS-PAGE gels for separation. Proteins were transferred to nitrocellulose membranes and blotted with DHFR antibody. Proteins were visualized using a Licor Odyssey. Alexa-Fluor 680 goat-anti-mouse IgG and IRDye $800 \mathrm{CW}$ goat-anti-rabbit IgG were used for detection. Beta-actin was used as a loading control. Westerns were quantified using Licor analysis. Statistical analysis was done using GraphPad Prism. ANOVA (one-way) was used to calculate significance respective to control. 


\section{Computational methods}

All calculations were performed using version 2019-1 of the Schrödinger Biologics and SmallMolecule suites. Ligands were drawn using MarvinSketch as .sdf files and imported into Maestro. Ligands were then prepared using the LigPrep protocol at $\mathrm{pH}$ 7.0. The dihedral driver protocol within MacroModel's Coordinate Scan program was then performed. The OPLS3 force field and water solvent system were used for all scans. All other parameters were left on default settings. For the biphenyl dihedral driver protocol, all atoms except the $\mathrm{C} 5^{\prime}$ of the proximal ring and all atoms in the distal ring, were frozen and the biphenyl dihedral angle was selected. For the propargyl linker dihedral driver protocol, the A ring and C7 of the propargyl linker were frozen and the propargylic dihedral angle was selected. The outputs of these dihedral drivers were then examined to determine the lowest energy state for each dihedral using the structure in Maestro as well as the coordinate plot generated in One Coordinate Scan Plot tool within MacroModel. 


\section{Synthetic Methods and Compound Characterization}

The ${ }^{1} \mathrm{H}$ and ${ }^{13} \mathrm{C}$ nuclear magnetic resonance (NMR) spectra were recorded on Bruker instruments at $500 \mathrm{MHz}$ and $126 \mathrm{MHz}$ respectively. Chemical shifts are reported in parts per million (ppm) and are referenced to residual DMSO solvent; $2.50 \mathrm{ppm}$ and $39.51 \mathrm{ppm}$ for ${ }^{1} \mathrm{H}$ and ${ }^{13} \mathrm{C}$ respectively. The high-resolution mass spectrometry was provided by the University of Connecticut Mass Spectrometry Laboratory using an AccuTOF mass spectrometer with an electrospray ionization (ESI) source. Compound purification was carried out in a Shimadzu preparative HPLC with Phenomenex Reverse Phase column (Synergi 4 Mm MAX-RP $80 \AA ̊$, $250 \mathrm{x}$ $21.20 \mathrm{~mm}$ ), and a UV/Vis detector using $254 \mathrm{~nm}$ and $218 \mathrm{~nm}$ wavelengths.

\section{4-\{7-[4-(2,4-diamino-6-ethylpyrimidin-5-yl)but-3-yn-2-yl]-2H-1,3-benzodioxol-5-yl\}benzoic acid (Compound 1)}

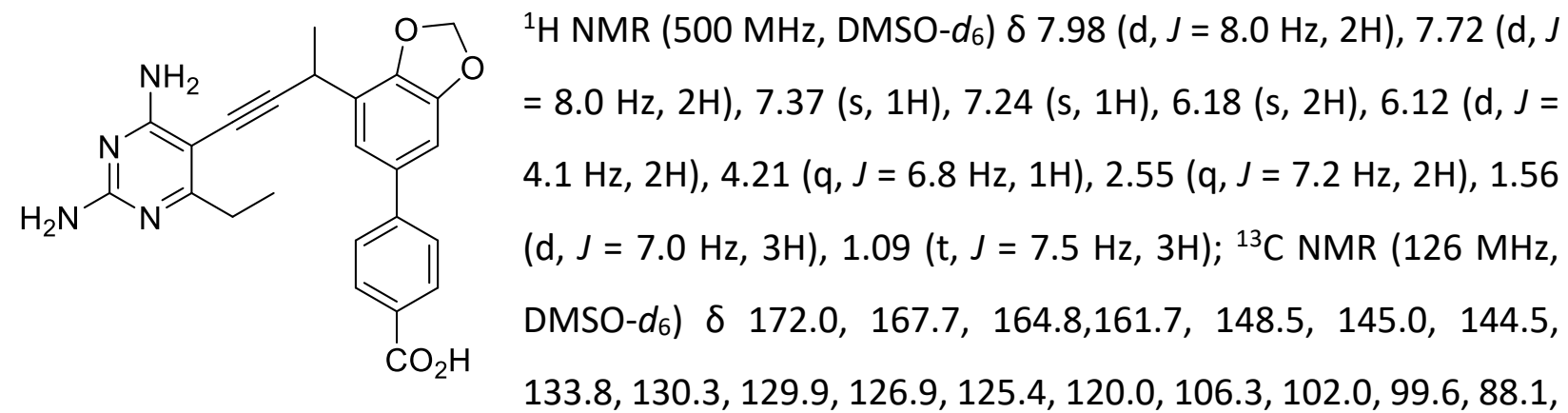
76.4, 29.3, 27.8, 22.7, 12.8; HRMS: ESI $(\mathrm{M}+\mathrm{H})^{+} \mathrm{m} / z$ calculated for $\mathrm{C}_{24} \mathrm{H}_{23} \mathrm{~N}_{4} \mathrm{O}_{4} 431.1708$, observed 431.1714; HPLC conditions: gradient $10-90 \%$ acetonitrile in water $+0.1 \% \mathrm{HCO}_{2} \mathrm{H}$, in 65 min at 8 $\mathrm{ml} / \mathrm{min}, t_{\mathrm{R}}=30.9 \mathrm{~min}$.

2-(4-\{7-[4-(2,4-diamino-6-ethylpyrimidin-5-yl)but-3-yn-2-yl]-2H-1,3-benzodioxol-5yl\}phenyl)acetic acid (Compound 2) 


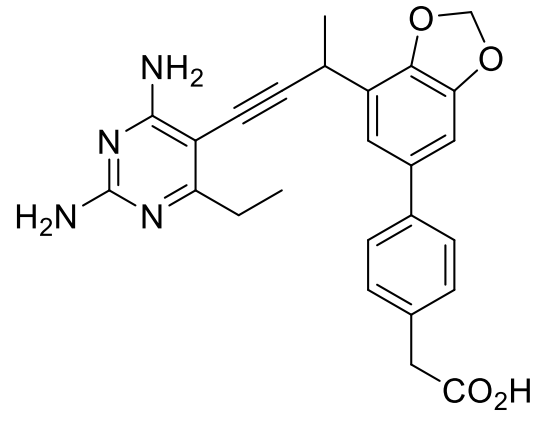

${ }^{1} \mathrm{H}$ NMR $\left(500 \mathrm{MHz}, \mathrm{DMSO}-d_{6}\right) \delta 7.53(\mathrm{~d}, J=8.0 \mathrm{~Hz}, 2 \mathrm{H}), 7.31$ $(\mathrm{d}, J=7.9 \mathrm{~Hz}, 2 \mathrm{H}), 7.26(\mathrm{~s}, 1 \mathrm{H}), 7.14(\mathrm{~s}, 1 \mathrm{H}), 6.16(\mathrm{~s}, 2 \mathrm{H}), 6.09$ $(\mathrm{s}, 2 \mathrm{H}), 4.20(\mathrm{q}, J=7.0 \mathrm{~Hz}, 1 \mathrm{H}), 3.59(\mathrm{~s}, 2 \mathrm{H}), 2.55(\mathrm{q}, J=7.4 \mathrm{~Hz}$, $2 \mathrm{H}), 1.55(\mathrm{~d}, J=7.0 \mathrm{~Hz}, 3 \mathrm{H}), 1.10(\mathrm{t}, J=7.5 \mathrm{~Hz}, 3 \mathrm{H}) ;{ }^{13} \mathrm{C} \mathrm{NMR}$ (126 MHz, DMSO-d6) $\delta 172.6,171.5,164.3,161.2,147.9$, $143.7,138.3,134.3,133.8,129.8,126.2,124.8,118.8,105.5$,

101.3, 99.2, 87.6, 75.8, 40.2, 40.01, 28.8, 27.4, 22.3, 12.3; HRMS: ESI $(M+H)^{+} m / z$ calculated for $\mathrm{C}_{25} \mathrm{H}_{25} \mathrm{~N}_{4} \mathrm{O}_{4} 445.1865$, observed 445.1880; HPLC conditions: gradient $10-90 \%$ acetonitrile in water $+0.1 \% \mathrm{HCO}_{2} \mathrm{H}$, in $65 \mathrm{~min}$ at $8 \mathrm{ml} / \mathrm{min}, t_{\mathrm{R}}=31.4 \mathrm{~min}$.

\section{2-\{3'-[4-(2,4-diamino-6-ethylpyrimidin-5-yl)but-3-yn-2-yl]-4'-methoxy-[1,1'-biphenyl]-4-} yl\}acetic acid (Compound 4)

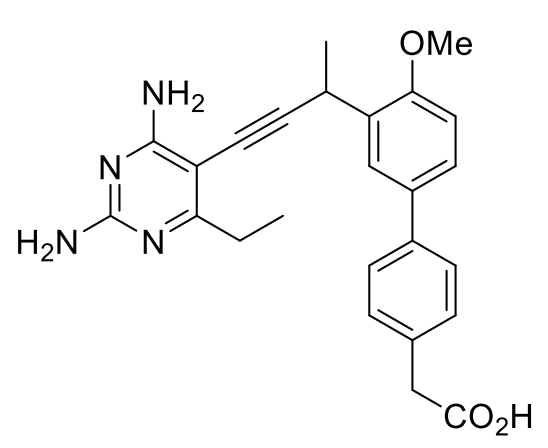

${ }^{1} \mathrm{H}$ NMR $\left(500 \mathrm{MHz}\right.$, DMSO- $\left.d_{6}\right) \delta 7.66(\mathrm{~d}, J=8.5 \mathrm{~Hz}, 2 \mathrm{H}), 7.35$ (d, $J=8.0 \mathrm{~Hz}, 2 \mathrm{H}), 7.18(\mathrm{~s}, 1 \mathrm{H}), 7.03(\mathrm{~s}, 1 \mathrm{H}), 6.08(\mathrm{~s}, 2 \mathrm{H}), 4.11$ (q, J = $7.0 \mathrm{~Hz}, 1 \mathrm{H}), 3.61(\mathrm{~s}, 2 \mathrm{H}), 2.66(\mathrm{q}, J=7.5 \mathrm{~Hz}, 2 \mathrm{H}), 1.54$ (d, $J=7.0 \mathrm{~Hz}, 3 \mathrm{H}), 1.16(\mathrm{t}, J=7.5 \mathrm{~Hz}, 3 \mathrm{H}) ;{ }^{13} \mathrm{C} \mathrm{NMR}(126 \mathrm{MHz}$, DMSO-d 6 ) $\delta 172.5,164.1,156.5,147.9,143.0,137.5,134.5$, 133.5, 129.6, 127.3, 121.2, 118.8, 106.4, 102.0, 100.9, 89.9, 73.1, 40.3, 31.8, 26.5, 24.2, 12.0; HRMS: ESI $(\mathrm{M}+\mathrm{H})^{+} \mathrm{m} / \mathrm{z}$ calculated for $\mathrm{C}_{25} \mathrm{H}_{27} \mathrm{~N}_{4} \mathrm{O}_{3}$ 431.2072, observed 431.2075; HPLC conditions: gradient 10-90\% acetonitrile in water $+0.1 \% \mathrm{HCO}_{2} \mathrm{H}$ in $35 \mathrm{~min}$ at $10 \mathrm{ml} / \mathrm{min}, t_{\mathrm{R}}=21.6 \mathrm{~min}$.

\section{4'-chloro-3'-[4-(2,4-diamino-6-ethylpyrimidin-5-yl)but-3-yn-2-yl]-[1,1'-biphenyl]-4-carboxylic} acid (Compound 5)<smiles>CCc1nc(N)nc(N)c1C#CC(C)c1cc(-c2ccc(C(=O)O)cc2)ccc1Cl</smiles>
${ }^{1} \mathrm{H}$ NMR $\left(500 \mathrm{MHz}, \mathrm{DMSO}-d_{6}\right) \delta 8.03(\mathrm{~s}, 3 \mathrm{H}), 7.81(\mathrm{~m}, 2 \mathrm{H}), 7.66$ (d, $\mathrm{J}=8.3 \mathrm{~Hz}, 1 \mathrm{H}), 7.58(\mathrm{~d}, \mathrm{~J}=8.3 \mathrm{~Hz}, 1 \mathrm{H}), 6.44$ (bs, 2H), $6.30(\mathrm{bs}, 2 \mathrm{H})$, $4.49(\mathrm{q}, \mathrm{J}=6.9 \mathrm{~Hz}, 1 \mathrm{H}), 2.56(\mathrm{~m}, 2 \mathrm{H}), 1.57(\mathrm{~d}, \mathrm{~J}=6.9 \mathrm{~Hz}, 3 \mathrm{H}), 1.08$ $(\mathrm{t}, \mathrm{J}=7.3 \mathrm{~Hz}, 3 \mathrm{H}) ;{ }^{13} \mathrm{C}$ NMR $\left(126 \mathrm{MHz}\right.$, DMSO- $\left.d_{6}\right) \delta 171.5,167.0$, $164.2,161.0,142.9,141.1,138.4,131.6,130.1,130.0,129.9$, 
127.1, 126.9, 126.6, 99.2, 87.3, 76.2, 29.9, 28.7, 22.4, 12.2; HRMS: ESI $m / z(M+H)^{+}$calculated for $\mathrm{C}_{23} \mathrm{H}_{22} \mathrm{ClN}_{4} \mathrm{O}_{2}$ 446.1896, observed 446.1904; HPLC conditions: gradient 10-90\% acetonitrile in water $+0.1 \% \mathrm{HCO}_{2} \mathrm{H}$, in $60 \mathrm{~min}$ at $10 \mathrm{ml} / \mathrm{min}, t_{\mathrm{R}}=28.3 \mathrm{~min}$.

\section{2-\{4'-chloro-3'-[4-(2,4-diamino-6-ethylpyrimidin-5-yl)but-3-yn-2-yl]-[1,1'-biphenyl]-4-yl\}acetic} acid (Compound 6)<smiles>CCc1nc(N)nc(N)c1C#CC(C)c1cc(-c2ccc(CC(=O)O)cc2)ccc1Cl</smiles>

${ }^{1} \mathrm{H}$ NMR (500 MHz, DMSO-d $\left.d_{6}\right) \delta .97(\mathrm{~s}, 1 \mathrm{H}), 7.61(\mathrm{~d}, J=8.0$ $\mathrm{Hz}, 2 \mathrm{H}), 7.59-7.51(\mathrm{~m}, 2 \mathrm{H}), 7.37(\mathrm{~d}, J=7.7 \mathrm{~Hz}, 2 \mathrm{H}), 6.35$ (bs, $2 \mathrm{H}), 6.19(\mathrm{~s}, 2 \mathrm{H}), 4.48(\mathrm{q}, J=6.9 \mathrm{~Hz}, 1 \mathrm{H}), 3.61(\mathrm{~s}, 2 \mathrm{H}), 2.58-$ $2.55(\mathrm{~m}, 2 \mathrm{H}), 1.54(\mathrm{~d}, J=7.0 \mathrm{~Hz}, 3 \mathrm{H}), 1.10(\mathrm{t}, J=7.5 \mathrm{~Hz}, 3 \mathrm{H})$; ${ }^{13} \mathrm{C}$ NMR $\left(126 \mathrm{MHz}, \mathrm{DMSO}-d_{6}\right) \delta 172.9,172.0,164.5,161.3$, $141.2,139.6,137.5,135.2,13.9,13.3,1302,126.9$, 126.7,99.7, 87.9, 76.3, 40.73, 30.19, 29.1, 22.8, 12.6; HRMS: ESI $(M+H)^{+} \mathrm{m} / \mathrm{z}$ calculated for $\mathrm{C}_{24} \mathrm{H}_{24} \mathrm{ClN}_{4} \mathrm{O}_{2}$ 446.1896, observed 446.1904; HPLC conditions: gradient 10-90\% acetonitrile in water $+0.1 \% \mathrm{HCO}_{2} \mathrm{H}$, in $60 \mathrm{~min}$ at $10 \mathrm{ml} / \mathrm{min}, t_{\mathrm{R}}=32.2 \mathrm{~min}$.

\section{2-\{3'-[4-(2,4-diamino-6-ethylpyrimidin-5-yl)but-3-yn-2-yl]-5'-methoxy-[1,1'-biphenyl]-4-} yl\}acetic acid (Compound 10)

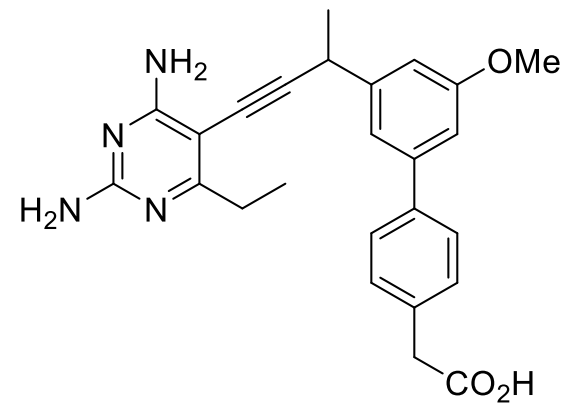

${ }^{1} \mathrm{H}$ NMR $\left(500 \mathrm{MHz}, \mathrm{DMSO}-d_{6}\right) \delta 7.60(\mathrm{~d}, J=7.0 \mathrm{~Hz}, 2 \mathrm{H}), 7.34$ (d, J = 7.0 Hz, 2H), $7.30(\mathrm{~s}, 1 \mathrm{H}), 7.03(\mathrm{~s}, 1 \mathrm{H}), 7.02(\mathrm{~s}, 1 \mathrm{H}), 6.14$ $(\mathrm{s}, 2 \mathrm{H}), 4.14(\mathrm{q}, J=6.9 \mathrm{~Hz}, 1 \mathrm{H}), 3.83(\mathrm{~s}, 3 \mathrm{H}), 3.60(\mathrm{~s}, 2 \mathrm{H}), 2.56$ (q, $J=7.4 \mathrm{~Hz}, 2 \mathrm{H}), 1.55(\mathrm{~d}, J=7.0 \mathrm{~Hz}, 3 \mathrm{H}), 1.11(\mathrm{t}, J=7.5 \mathrm{~Hz}$, $3 \mathrm{H}) ;{ }^{13} \mathrm{C}$ NMR (125 MHz, DMSO-d $) \delta 172.5,164.1,156.5$, $147.9,143.0,137.5,134.5,133.5,129.6,127.3,121.2,118.8$, 106.4, 102.0, 100.9, 89.9, 73.1, 40.3, 31.8, 26.5, 24.2, 12.0; HRMS: ESI $(M+H)^{+} \mathrm{m} / z$ calculated for $\mathrm{C}_{25} \mathrm{H}_{27} \mathrm{~N}_{4} \mathrm{O}_{3}$ 431.2072, observed 431.2086; HPLC conditions: gradient 10-90\% acetonitrile in water $+0.1 \% \mathrm{HCO}_{2} \mathrm{H}$, in $55 \mathrm{~min}$ at $8 \mathrm{ml} / \mathrm{min}, t_{\mathrm{R}}=28.3 \mathrm{~min}$. 
2-\{3'-[(2R)-4-(2,4-diamino-6-ethylpyrimidin-5-yl)but-3-yn-2-yl]-5'-methoxy-[1,1'-biphenyl]-4yl\}acetic acid (Compound 11)<smiles>CCc1nc(N)nc(N)c1C#C[C@H](C)c1cc(OC)cc(-c2ccc(CC(=O)O)cc2)c1</smiles>

$[\alpha]_{D}{ }^{20}:+12.0(c$ 1.4, $\mathrm{CHCl} 3) ;{ }^{1} \mathrm{H}$ NMR and ${ }^{13} \mathrm{C}$ NMR: Same as 10; HRMS: ESI $(\mathrm{M}+\mathrm{H})^{+} \mathrm{m} / \mathrm{z}$ calculated for $\mathrm{C}_{25} \mathrm{H}_{27} \mathrm{~N}_{4} \mathrm{O}_{3}$ 431.2072, observed 446.1904; HPLC conditions: gradient $10-90 \%$ acetonitrile in water $+0.1 \% \mathrm{HCO}_{2} \mathrm{H}$, in 55 min at 8 $\mathrm{ml} / \mathrm{min}, t_{\mathrm{R}}=28.2 \mathrm{~min}$.

\section{2-\{3'-[(2S)-4-(2,4-diamino-6-ethylpyrimidin-5-yl)but-3-yn-2-yl]-5'-methoxy-[1,1'-biphenyl]-4-} yl\}acetic acid (Compound 12)<smiles>CCc1nc(N)nc(N)c1C#CC(C)c1cc(OC)cc(-c2ccc(CC(=O)O)cc2)c1</smiles>
$[\alpha]_{D}^{20}:+12.0(c$ 1.4, $\mathrm{CHCl} 3) ;{ }^{1} \mathrm{H}$ NMR and ${ }^{13} \mathrm{C}$ NMR: Same as 10; HRMS: ESI $(\mathrm{M}+\mathrm{H})^{+} \mathrm{m} / \mathrm{z}$ calculated for $\mathrm{C}_{25} \mathrm{H}_{27} \mathrm{~N}_{4} \mathrm{O}_{3}$ 431.2072, observed 446.1904; HPLC conditions: gradient $10-90 \%$ acetonitrile in water $+0.1 \% \mathrm{HCO}_{2} \mathrm{H}$, in 55 min at 8 $\mathrm{ml} / \mathrm{min}, t_{\mathrm{R}}=28.0 \mathrm{~min}$.

\section{2-(4-\{6-[4-(2,4-diamino-6-ethylpyrimidin-5-yl)but-3-yn-2-yl]-2H-1,3-benzodioxol-4-} yl\}phenyl)acetic acid (Compound 14)<smiles>CCc1nc(N)nc(N)c1C#CC(C)c1cc2c(c(-c3ccc(CC(=O)O)cc3)c1)OCO2</smiles>

${ }^{1} \mathrm{H}$ NMR (500 MHz, DMSO- $\left.d_{6}\right) \delta 7.66(\mathrm{~d}, J=8.5 \mathrm{~Hz}, 2 \mathrm{H}), 7.35$ $(\mathrm{d}, J=8.0 \mathrm{~Hz}, 2 \mathrm{H}), 7.18(\mathrm{~s}, 1 \mathrm{H}), 7.03(\mathrm{~s}, 1 \mathrm{H}), 6.08(\mathrm{~s}, 2 \mathrm{H}), 4.11$ $(q, J=7.0 \mathrm{~Hz}, 1 \mathrm{H}), 3.61(\mathrm{~s}, 2 \mathrm{H}), 2.66(\mathrm{q}, J=7.5 \mathrm{~Hz}, 2 \mathrm{H}), 1.54$ (d, $J=7.0 \mathrm{~Hz}, 3 \mathrm{H}), 1.16(\mathrm{t}, J=7.5 \mathrm{~Hz}, 3 \mathrm{H}) ;{ }^{13} \mathrm{C}$ NMR $(125 \mathrm{MHz}$, DMSO- $\left.d_{6}\right) \delta 172.5,164.1,156.5,147.9,143.0,137.5,134.5$, $133.5,129.6,127.3,121.2,118.8,106.4,102.0,100.9$, 89.9,

73.1, 40.3, 31.8, 26.5, 24.2, 12.0; HRMS: DART $(\mathrm{M}+\mathrm{H})^{+} \mathrm{m} / \mathrm{z}$ calculated for $\mathrm{C}_{25} \mathrm{H}_{25} \mathrm{~N}_{4} \mathrm{O}_{4} 445.1865$, observed 445.1874; HPLC conditions: gradient 10-90\% acetonitrile in water $+0.1 \% \mathrm{HCO}_{2} \mathrm{H}$, in 65 $\min$ at $10 \mathrm{ml} / \mathrm{min}, t_{\mathrm{R}}=27.6 \mathrm{~min}$. 


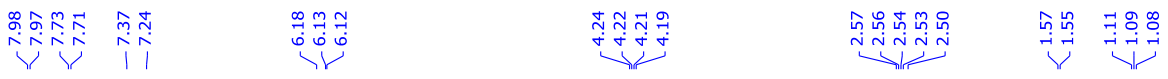
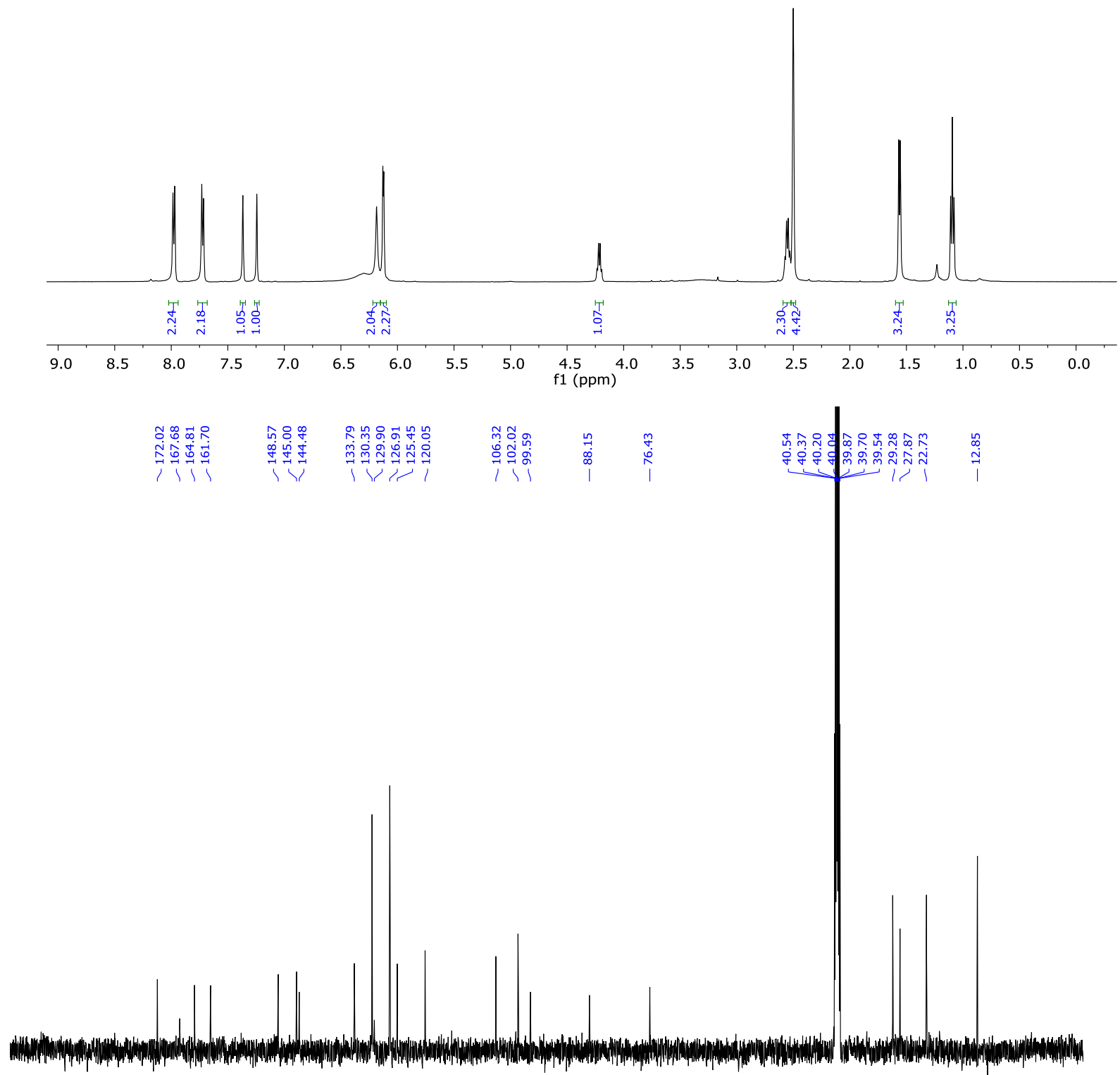

$\begin{array}{lllllllllll}00 & 190 & 180 & 170 & 160 & 150 & 140 & 130 & 120 & 110 & 100 \\ \mathrm{f} 1(\mathrm{ppm})\end{array}$

Supplemental Figure 8: ${ }^{1} \mathrm{H}$ and ${ }^{13} \mathrm{C}$ NMR for 1 

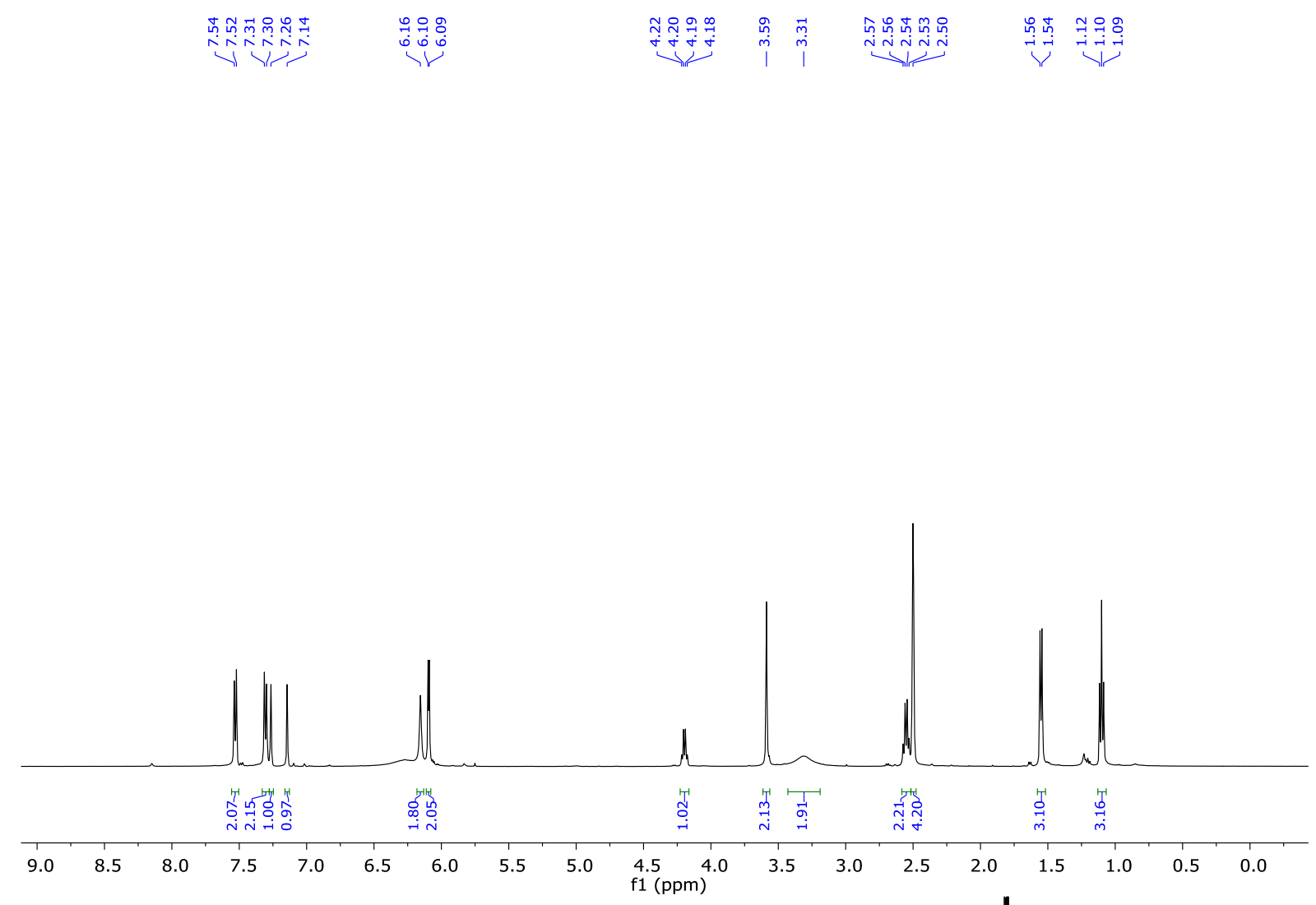

\begin{tabular}{|c|c|c|c|c|c|c|c|c|}
\hline 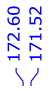 & 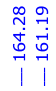 & 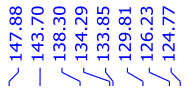 & $\begin{array}{l}\dot{ } \\
\infty \\
\infty \\
\Rightarrow \\
\Rightarrow\end{array}$ & 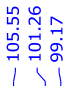 & $\begin{array}{c}\underset{+}{0} \\
\stackrel{\infty}{\infty} \\
1\end{array}$ & 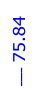 & 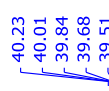 & 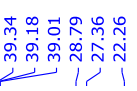 \\
\hline
\end{tabular}

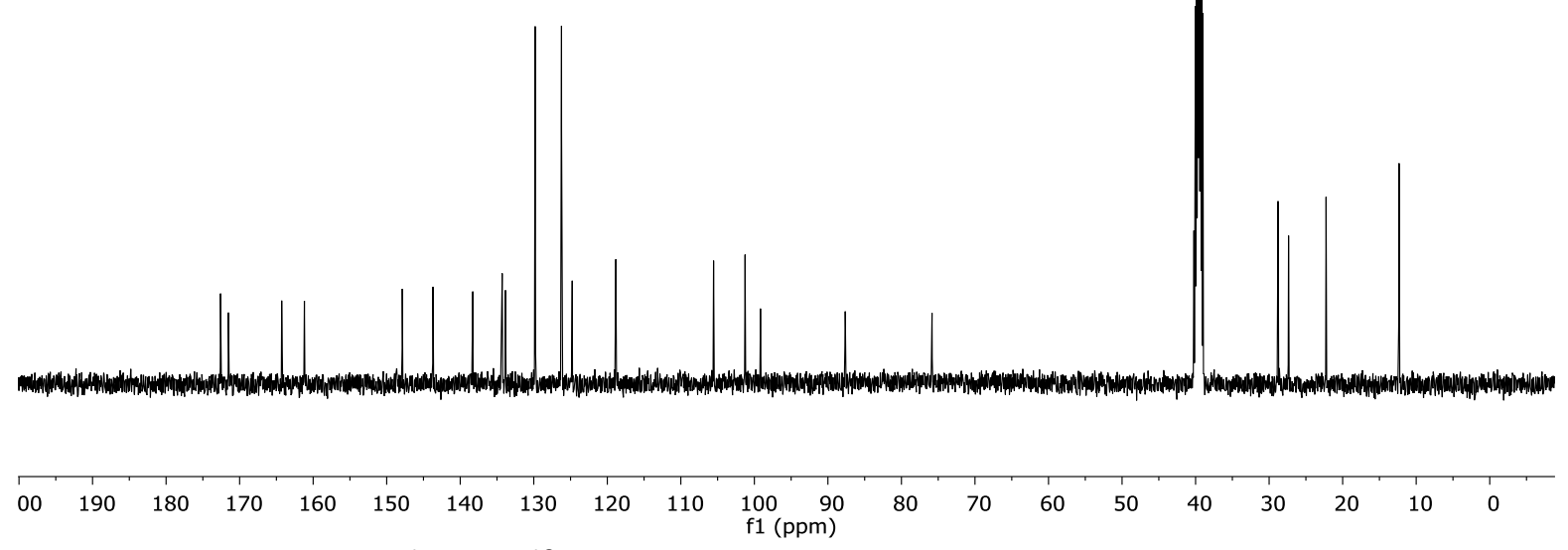

Supplemental Figure 11: ${ }^{1} \mathrm{H}$ and ${ }^{13} \mathrm{C}$ NMR for 2 


\begin{tabular}{|c|c|c|}
\hline 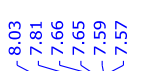 & 声勇 & 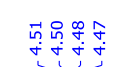 \\
\hline
\end{tabular}
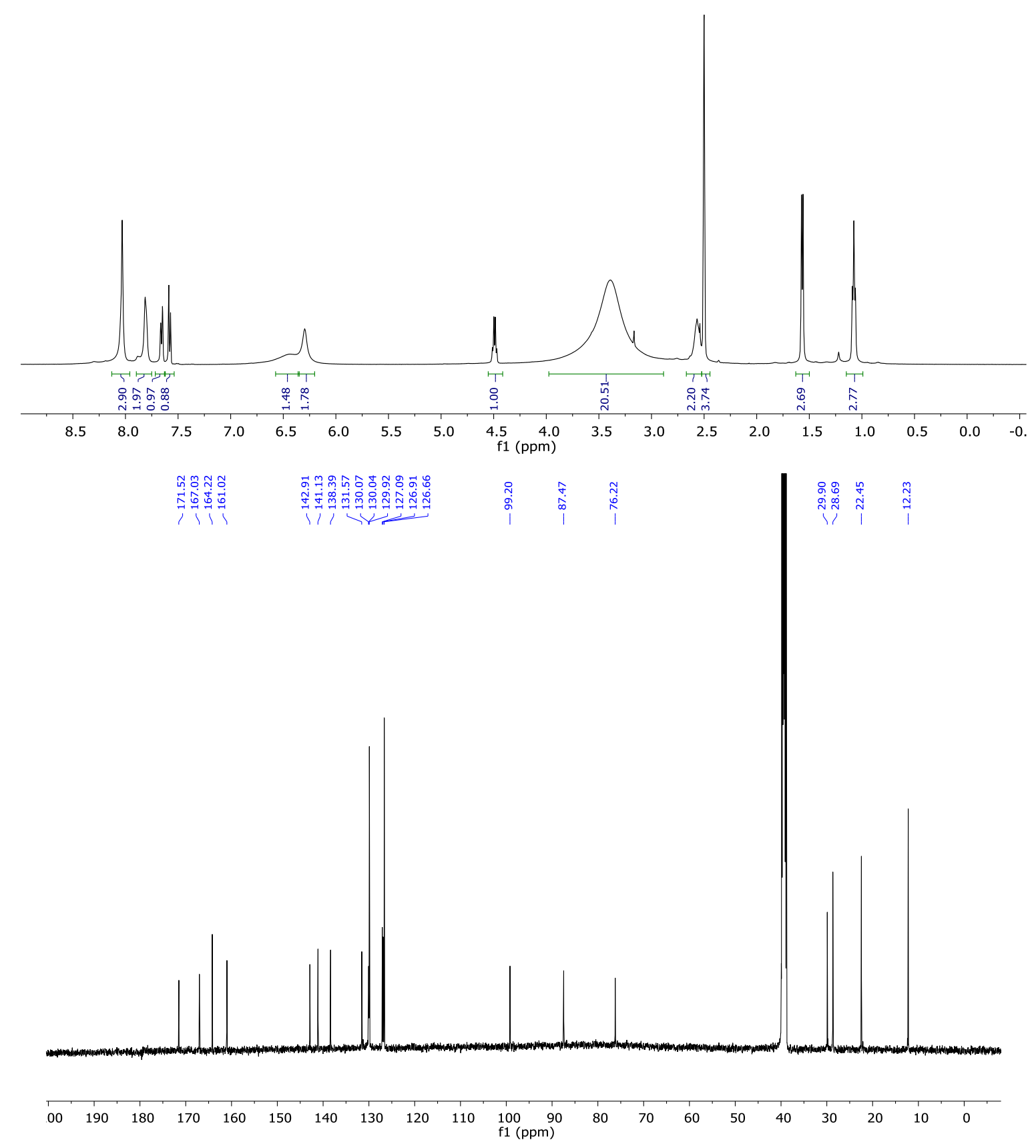

Supplemental Figure 7: ${ }^{1} \mathrm{H}$ and ${ }^{13} \mathrm{C}$ NMR for 5 


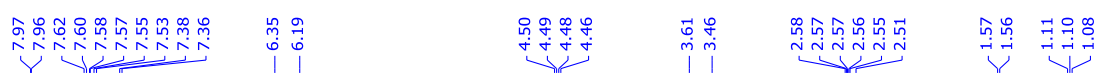
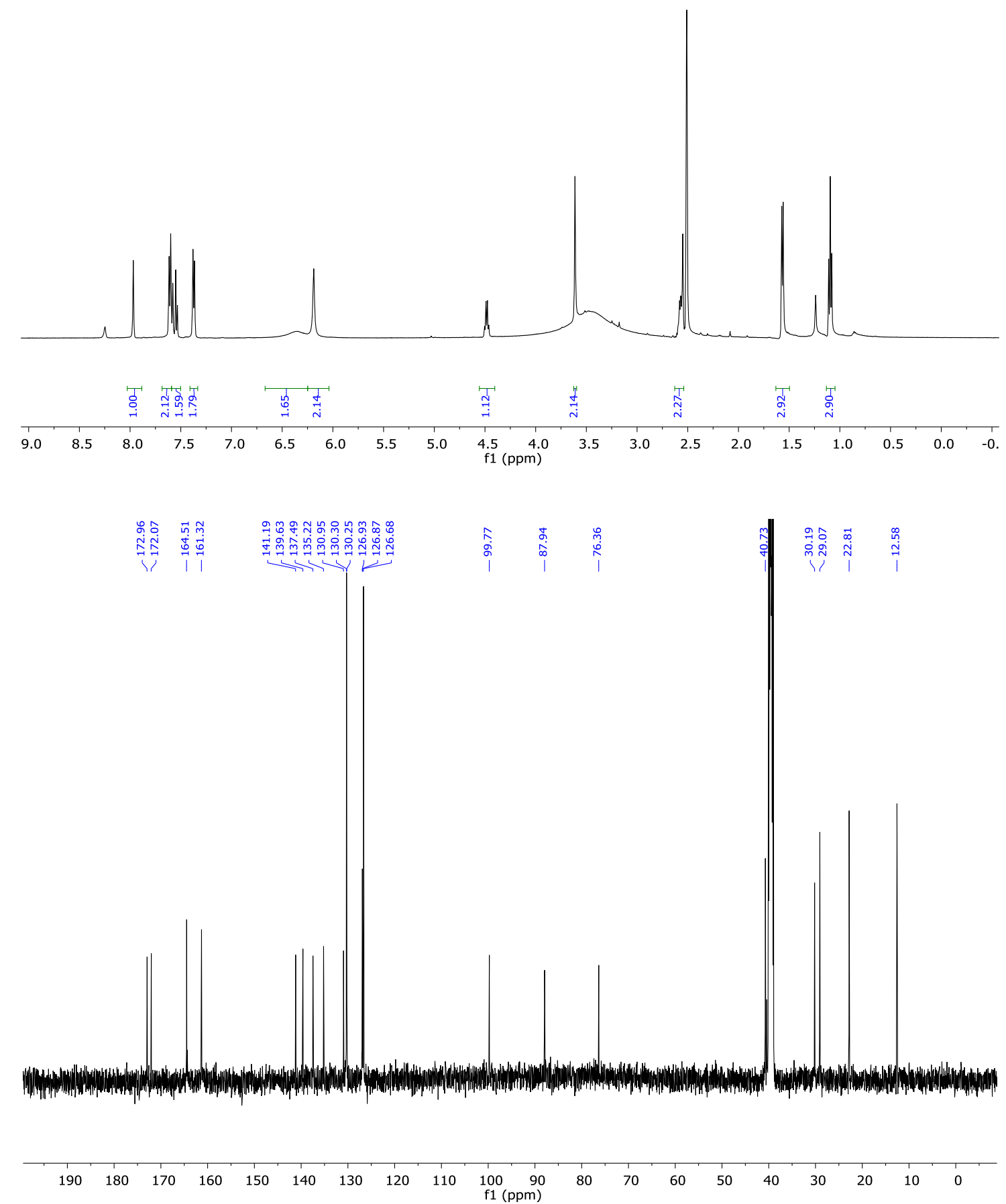

Supplemental Figure 9: ${ }^{1} \mathrm{H}$ and ${ }^{13} \mathrm{C}$ NMR for 6 

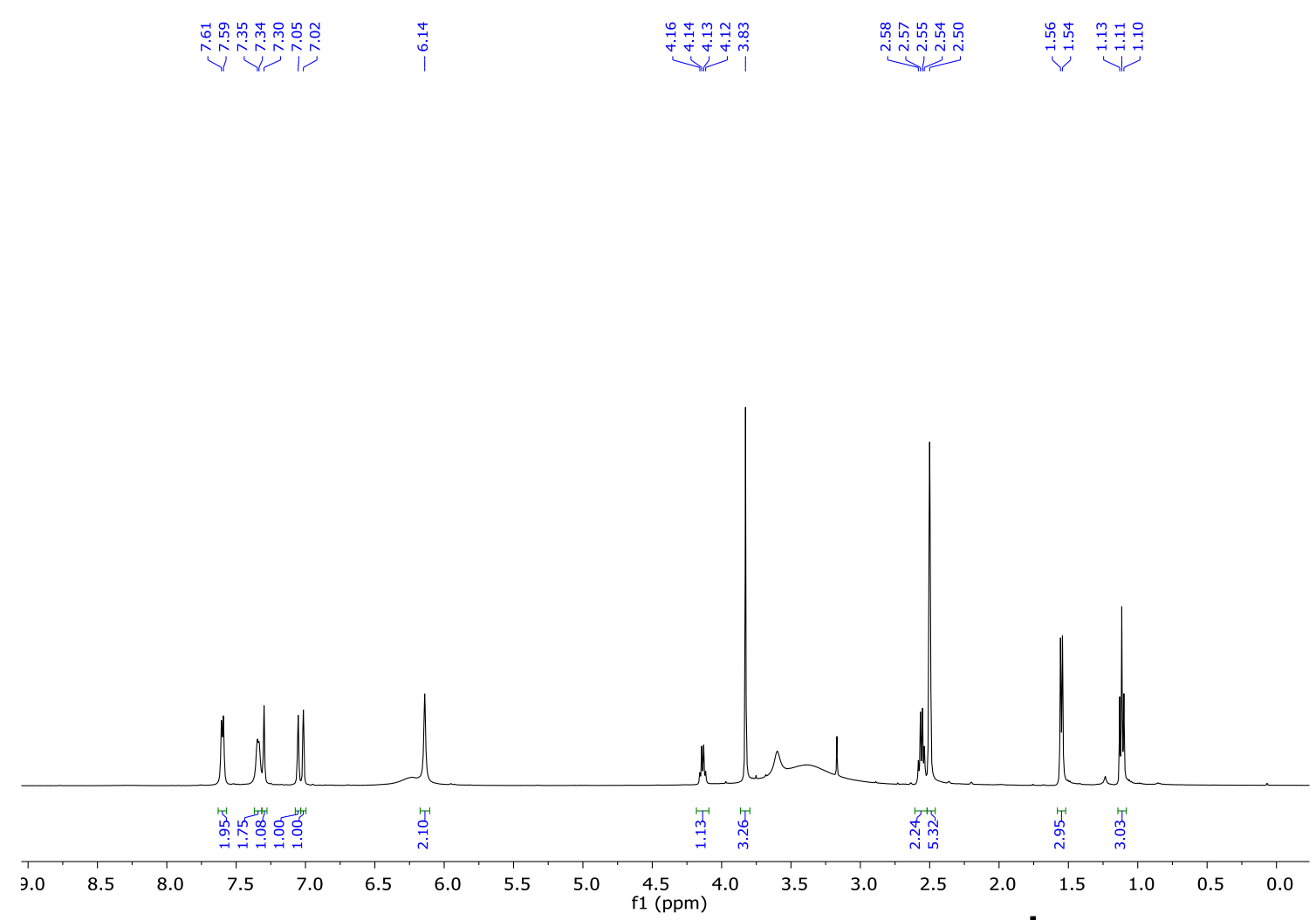

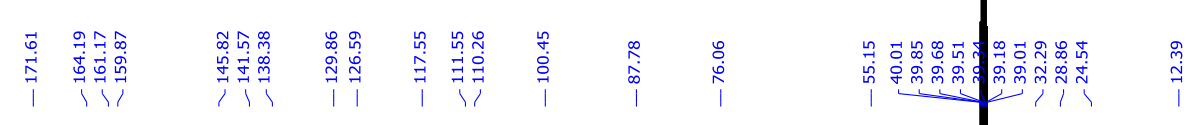
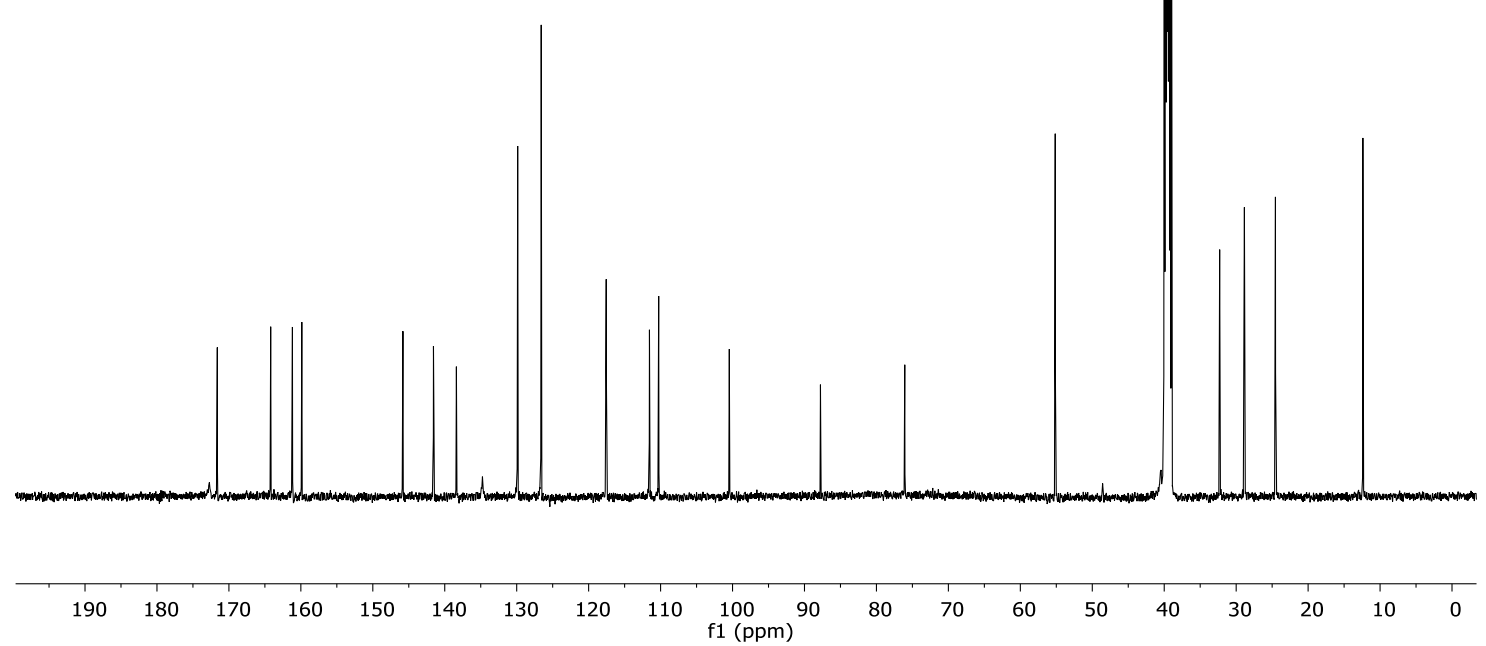

Supplemental Figure 10: ${ }^{1} \mathrm{H}$ and ${ }^{13} \mathrm{C}$ NMR for 10 

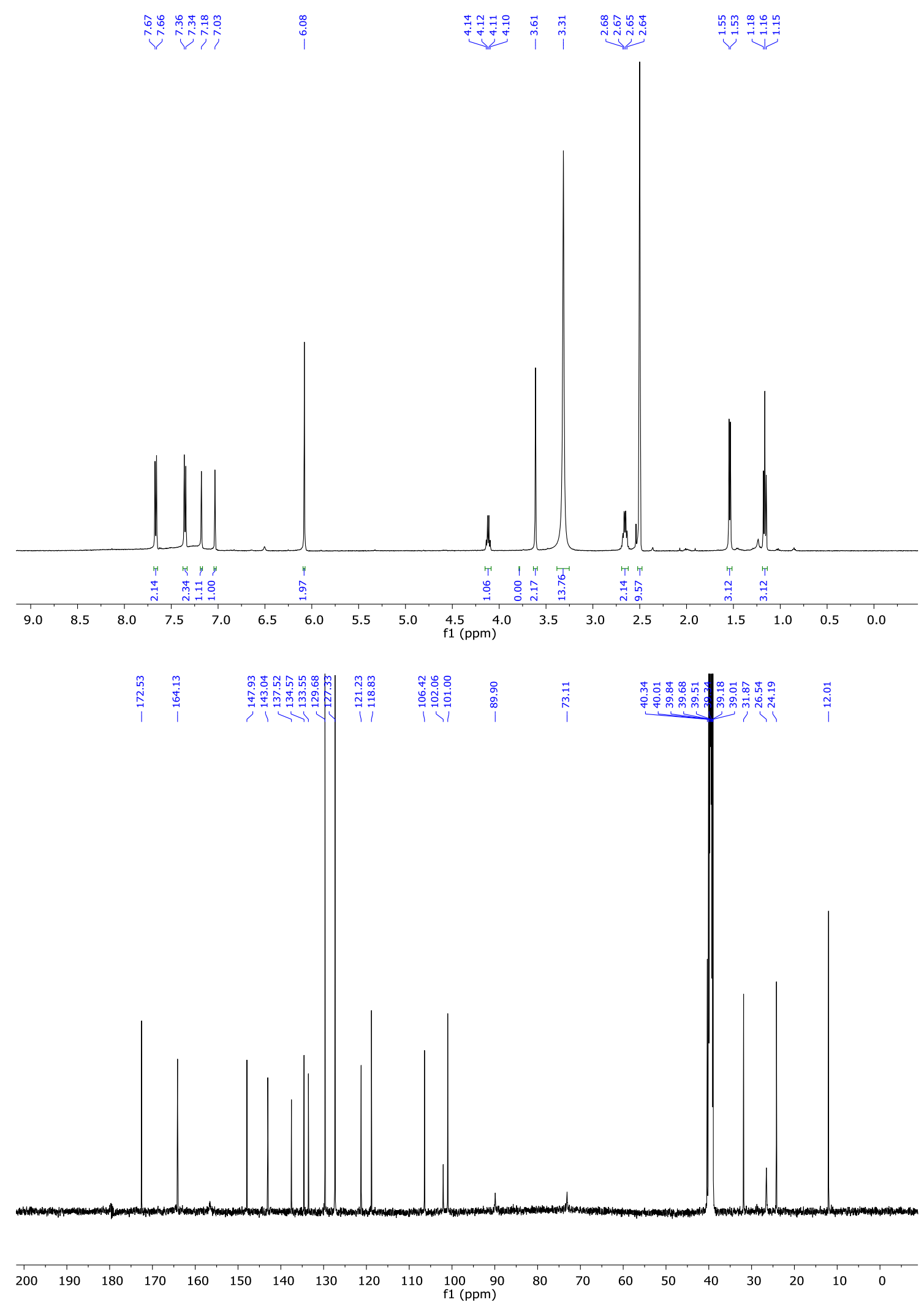

Supplemental Figure 12: ${ }^{1} \mathrm{H}$ and ${ }^{13} \mathrm{C}$ NMR for 14 